\title{
Investigating the Use of Thinking Aloud Protocols in Translation of Literary Texts
}

\author{
Ali Asghar Eftekhary \\ English Department, Faculty of Foreign Languages, Islamic Azad University, Bandar Abbas Branch, Iran \\ Email: Ali.Eftekhary90@gmail.com \\ Shayesteh Aminizadeh \\ Islamic Azad University, Bandar Abbas Branch, Iran \\ Email: Shayesteh_Aminizadeh@yahoo.com
}

\begin{abstract}
Mental constructs and processes in general and translation processes in particular have been the focus of much research in the past three decades. Among the techniques used in studying such cognitive processes and strategies, the use of Thinking Aloud Protocols (TAPs), has extensively been proposed. Though much has been written on the use of TAPs in recognizing the mental processes translators experience, very little if any can be found to address the mechanisms and mental processes they undergo while translating a piece of literary text. Having this in mind, the purpose of the present study was to investigate the strategies senior translation students of Islamic Azad University, Bandar Abbas Branch apply while translating literary texts using Thinking Aloud Protocols. To achieve this end, 12 senior translation students of Islamic Azad University, Bandar Abbas Branch participated in the study. Participants were chosen according to the convenience sampling method. The subjects, then were asked to translate four literary texts and while translating verbalize whatever goes on in their mind within a TAP framework. The "think aloud protocols" were categorized based on the frequency table and the translations were analyzed qualitatively. The data was analyzed to reveal the strategies used by the respondents. In the analysis of the strategies, just the types of strategies were of importance to the researcher though the frequency of each strategy was also, collected and reported. Based on the findings, fourteen strategies were detected with Look-up was as the most frequent strategy used by the subjects in the study .Using imagery and Paraphrasing were the second and third most frequent strategies used by the subjects respectively. Switching to $L 1$ while translation was found the lowest strategy as reported in TAPs by the subjects. Deductive reasoning strategies were the second lowest strategy reported. Such strategies as Resourcing and referencing, evaluating and monitoring, problem solving and cotext recourse stood in between.
\end{abstract}

Index Terms - think-aloud protocol (TAP), translation process, literary text

\section{INTRODUCTION}

Mental constructs and processes in general and translation processes in particular have been the focus of much research in the past three decades. (Kussmaul and Tirkkonen-Condit, 1995; Pöntinen and Romanov, 1989; Jääskeläinen, 1999; Jensen, 1999; Künzli 2007 among others). To date many speculations have been proposed on what might occur in the translator's mind during translation. Human cognitive processes - and particularly the mental process of translation can be investigated in different ways such as observing reactions to specific stimuli, analyzing the errors and the results of a task performance, etc. Over the last three decades, however, think-aloud protocols (TAPs) have become a widelyused method to investigate the complex process of translation. This method allows data collection about the translator's thoughts at the same time he verbalizes them. The focus on such techniques has its roots on the way translation is defined and conceptualized in the field. To many translation theorists, translation is a process, in which we should transfer meaning and sense of the source language into the target language, and to the extent that we can attain this objective, our translation would be more acceptable. Again, since this process is a science and art due to its characteristics, the translator should be able to master the target language grammar and writing skill to transfer this actual sense completely. On the other hand, translation is a process between two languages and the translator has to produce a bridge between these two and for strengthening this bridge and reaching the aim of translation, the translator should be familiar with the culture, grammar and other characteristics of the source and target language and be able to process all these appropriately. According to Jackobson (1959), translation is whole message transference from one language into another rather than the transfusion of single separate code units. He, also, believes that what the translator does is understanding the whole message of source language and transferring it into the target language. Hence, understanding the sense and aim of the source language is the main task of the translator which is a process than a mere product.

So, the translator stands at the centre of the complex process of translation, as a mediator between the producer of the source text and its target language readers. The translator is first and foremost a mediator between two parties for whom 
mutual communication might otherwise be problematic. (Hatim \& Mason, 1990). Translation theories are fundamentally concerned with rendering a source language to a target language. Different translation theorists have expressed different views on what the characteristics of a good translator should be. But something has commonly been agreed upon and that is the fact that more knowledge of the language can not by itself be sufficient to make one capable of handling translation from the source language into the target language (Miremadi, 2001) if the very process of translation is ignored. The tasks gets much more complicated when the type and genre of the translation requires quite different mental strategies for rendering the given text or texts. One such type of texts is the literary text which seems to require more demanding mental processes in translation compared with other genres due mainly to the complex interaction of language and culture in such texts.

In 1990, Susan Bassnett and André Lefevere announced that neither the word, nor the text, but the culture becomes the operational 'unit' of translation. Herzfeld (2003) states that a literary translation is a device of art used to release the text from its "dependence on prior cultural knowledge. However, it is not an easy task to transplant a text steeped in one culture into another. Particularly demanding from the translator's point of view is the use of culturally specific metaphors and allusions. As Kussmaul and Tirkkonen-Condit, (1995) argue There has always been a kind of empirical research, like translation criticism and error analysis, but this was product- and not process- oriented. By comparing the target text with the source text or looking at errors of the translated text, one could only speculate about what has occurred in the translator's mind during translation. What was needed was a way to discover what actually happens, to get a glimpse into the 'black box'.

As it was stated above such a view towards translation led to a surge of interest into finding and applying techniques which could unravel the processes which the translator underwent to render a piece of texts. One such technique was the use of thinking aloud protocols.

\section{Methodology}

The project was discussed with the senior students majoring in English translation at Islamic Azad University, Bandar Abbas Branch. 12 students voluntarily took part in the first phase of the study based on a convenience sampling method. Participants were trained how to present think aloud protocols in two sessions of training and practicing it one by one in the classroom. Then they were given four literary excerpts taken from four great short stories. Both the stories and the excerpts were extracted on a random basis. Due to the nature of literary texts, readability index was not taken into account in this study to observe the authenticity of the texts. The participants were asked to translate the texts from English to Persian and keep records of their first drafts including corrections, crosses, and developmental stages of their work up to the end of the exam session. They were also asked to provide the researcher with the think- aloud protocols in Persian and in their own handwritings. The data were collected, categorized and analyzed. The "think aloud protocols" were categorized based on the frequency table and the translations were analyzed qualitatively.

\section{Material}

A translation test consisting of four literary excerpts was the main instrument of the study. The texts completed through TAPs protocols were The Death of Ivan Ilyich by Leo Tolstoy, The Dead by James Joyce, The Cask of Amontillado by Edgar Allan Poe and Young Goodman Brown by Nathaniel Hawthorne .They were taken randomly out of a pool of 75 great short stories from the following website: www.theshortstory.org

\section{DISCUSSION}

This study investigated the strategies senior translation students of Islamic Azad University, Bandar Abbas Branch apply while translation of literary texts using Thinking Aloud Protocols. In so doing, first the results of the study are summarized in Table.1 followed by a more detailed elaboration and argumentation. Finally, conclusion, implication, and limitations of the study are presented.

Table.1 summarizes the results of subjects' verbalization of strategies they have used while translating the literary excerpts they received in the study. 
TABLE. 1

THE STRATEGIES USED BY THE PARTICIPANTS IN THEIR TAPS

\begin{tabular}{|l|l|l|l|l|l|l|l|l|l|l|l|l|}
\hline Strategies applied & S1 & S2 & S3 & S4 & S5 & S6 & S7 & S 8 & S9 & S 10 & S11 & S12 \\
\hline Using Imagery & $\mathbf{8}$ & $\mathbf{7}$ & $\mathbf{1 0}$ & $\mathbf{9}$ & $\mathbf{8}$ & $\mathbf{6}$ & $\mathbf{7}$ & $\mathbf{7}$ & $\mathbf{9}$ & $\mathbf{8}$ & $\mathbf{6}$ & $\mathbf{5}$ \\
\hline Analysing \&Reasoning & $\mathbf{4}$ & $\mathbf{5}$ & $\mathbf{3}$ & $\mathbf{6}$ & $\mathbf{5}$ & $\mathbf{5}$ & $\mathbf{5}$ & $\mathbf{4}$ & $\mathbf{6}$ & $\mathbf{3}$ & $\mathbf{5}$ & $\mathbf{6}$ \\
\hline Contextual recourse & $\mathbf{7}$ & $\mathbf{6}$ & $\mathbf{5}$ & $\mathbf{5}$ & $\mathbf{6}$ & $\mathbf{6}$ & $\mathbf{4}$ & $\mathbf{5}$ & $\mathbf{5}$ & $\mathbf{3}$ & $\mathbf{3}$ & $\mathbf{4}$ \\
\hline Look-up & $\mathbf{1 2}$ & $\mathbf{1 2}$ & $\mathbf{1 3}$ & $\mathbf{1 1}$ & $\mathbf{9}$ & $\mathbf{1 0}$ & $\mathbf{1 2}$ & $\mathbf{1 1}$ & $\mathbf{1 0}$ & $\mathbf{9}$ & $\mathbf{8}$ & $\mathbf{1 0}$ \\
\hline Resourcing \& referencing & $\mathbf{7}$ & $\mathbf{5}$ & $\mathbf{4}$ & $\mathbf{8}$ & $\mathbf{6}$ & $\mathbf{6}$ & $\mathbf{6}$ & $\mathbf{6}$ & $\mathbf{4}$ & $\mathbf{7}$ & $\mathbf{2}$ & $\mathbf{6}$ \\
\hline Self-recourse & $\mathbf{7}$ & $\mathbf{9}$ & $\mathbf{5}$ & $\mathbf{7}$ & $\mathbf{6}$ & $\mathbf{4}$ & $\mathbf{4}$ & $\mathbf{5}$ & $\mathbf{7}$ & $\mathbf{6}$ & $\mathbf{5}$ & $\mathbf{3}$ \\
\hline Switching to L1 & $\mathbf{3}$ & $\mathbf{3}$ & $\mathbf{2}$ & $\mathbf{1}$ & $\mathbf{3}$ & $\mathbf{5}$ & $\mathbf{4}$ & $\mathbf{3}$ & $\mathbf{2}$ & $\mathbf{2}$ & $\mathbf{3}$ & $\mathbf{1}$ \\
\hline Paraphrasing & $\mathbf{9}$ & $\mathbf{8}$ & $\mathbf{8}$ & $\mathbf{9}$ & $\mathbf{1 0}$ & $\mathbf{6}$ & $\mathbf{8}$ & $\mathbf{7}$ & $\mathbf{6}$ & $\mathbf{8}$ & $\mathbf{6}$ & $\mathbf{7}$ \\
\hline Guessing Game & $\mathbf{4}$ & $\mathbf{6}$ & $\mathbf{5}$ & $\mathbf{7}$ & $\mathbf{3}$ & $\mathbf{5}$ & $\mathbf{3}$ & $\mathbf{2}$ & $\mathbf{6}$ & $\mathbf{5}$ & $\mathbf{4}$ & $\mathbf{3}$ \\
\hline Problem solving & $\mathbf{8}$ & $\mathbf{6}$ & $\mathbf{5}$ & $\mathbf{6}$ & $\mathbf{5}$ & $\mathbf{6}$ & $\mathbf{7}$ & $\mathbf{3}$ & $\mathbf{8}$ & $\mathbf{5}$ & $\mathbf{4}$ & $\mathbf{6}$ \\
\hline Inductive inferencing & $\mathbf{5}$ & $\mathbf{4}$ & $\mathbf{8}$ & $\mathbf{4}$ & $\mathbf{5}$ & $\mathbf{4}$ & $\mathbf{4}$ & $\mathbf{5}$ & $\mathbf{5}$ & $\mathbf{4}$ & $\mathbf{4}$ & $\mathbf{2}$ \\
\hline Deductive reasoning & $\mathbf{4}$ & $\mathbf{3}$ & $\mathbf{3}$ & $\mathbf{3}$ & $\mathbf{4}$ & $\mathbf{2}$ & $\mathbf{2}$ & $\mathbf{4}$ & $\mathbf{5}$ & $\mathbf{2}$ & $\mathbf{4}$ & $\mathbf{4}$ \\
\hline Co-text Recourse & $\mathbf{7}$ & $\mathbf{5}$ & $\mathbf{6}$ & $\mathbf{6}$ & $\mathbf{8}$ & $\mathbf{6}$ & $\mathbf{4}$ & $\mathbf{6}$ & $\mathbf{6}$ & $\mathbf{7}$ & $\mathbf{5}$ & $\mathbf{5}$ \\
\hline Evaluating \& monitoring & $\mathbf{8}$ & $\mathbf{6}$ & $\mathbf{8}$ & $\mathbf{7}$ & $\mathbf{6}$ & $\mathbf{6}$ & $\mathbf{7}$ & $\mathbf{7}$ & $\mathbf{6}$ & $\mathbf{5}$ & $\mathbf{8}$ & $\mathbf{7}$ \\
\hline Other Compensation & $\mathbf{4}$ & $\mathbf{4}$ & $\mathbf{6}$ & $\mathbf{5}$ & $\mathbf{3}$ & $\mathbf{5}$ & $\mathbf{5}$ & $\mathbf{6}$ & $\mathbf{2}$ & $\mathbf{5}$ & $\mathbf{4}$ & $\mathbf{5}$ \\
Strategies e.g. Association & & & & & & & & & & & \\
\hline
\end{tabular}

As it can be seen from the table.1, subjects have employed variety of cognitive, met cognitive and compensation strategies in the translation of the literary excerpts.

Based on the frequency of the reports, the main translation strategies which subjects had resorted to while translating the literary texts were:

1. Look-Up (127 times)

2. Using Imagery (109)

3. Paraphrasing (92)

4. Evaluating and Monitoring (81)

5. Co-text Recourse (71)

6. Problem Solving (69)

7. Self-Recourse (68)

7. Resourcing and referencing (67)

8. Contextual Recourse (59)

9. Analyzing and Reasoning (57)

10. Inductive Inferencing (54)

11. Other Compensation Strategies (54)

12. Guessing Games (53)

13. Deductive Inferencing (40)

14. Switching to L1 ( 32 )

These findings are in line with the previous research while the terminology adopted in this study is a little bit different from some seminal models in the literature. For example Krings (1986) offers the following list of translation strategies reported in TAPs:

1. The subjects' explicit statement of problems

2. The use of reference books

3. The underlining of source-language text passages

4. The semantic analysis of source-language text items

5. Hesitation phenomena in the search for potential equivalents

6. Competing potential equivalents

7. The monitoring of potential equivalents

8. Using Specific translation principles

9. The modification of written target-language texts

10.The assessment of the quality of the chosen translation

11. Paralinguistic or non-linguistic features (Krings, 1986: 267)

As for those translation strategies, which subjects resort to when automatic processing breaks down, Krings suggests that these can be classified as strategies of comprehension

(Inferencing and use of reference works), equivalent retrieval (especially interlingual and intralingual associations), equivalent monitoring (such as comparing Source Text (ST) and Target Text (TT)), decision-making (choosing between two equivalent solutions) and reduction (for instance of marked or metaphorical text portions).

Again as it can be seen, some of these strategies though the terminology is a bit different. For example, for comprehension strategies, inferencing, inductive and deductive reasoning have been used in the study for equivalent retrieval and equivalent monitoring, paraphrasing, self recourse and evaluation have been proposed based on Oxford's 1990 classification of cognitive and metacognitive strategies as translation process is assumed to involve such mental routes. 
There are other classifications too. For example one has been proposed by Gerloff (1986) who defines textprocessing strategies as any metalinguistic or metacognitive comments made or specific problem-solving behaviors affected, during the decoding and rendering of the translation text. The strategies she suggests are:

1. Problem identification

2. Linguistic analysis

3. Storage and retrieval

4. General search and selection

5. Text inferencing and reasoning

6. Text contextualization

7. Task monitoring.

While inferencing, reasoning, monitoring, and analyzing are more or the less the same terminology as has been reported in chapter four of this study, with some modification, other strategies too can be mapped on what has been found in the study under investigation. It goes without saying that, due to the nature of the genre in this study, there are some strategies which can be argued to be attributed to literary texts. for example, using imagery is a strategy been resorted to in many cases by the subjects while translating the literary excerpts. Self recourse and contextual resorts are other examples.

Mondhal and Jensen (1996), further, distinguish production from evaluation strategies. The former are further subdivided into achievement strategies and reduction strategies .Among achievement strategies, which are characterized by an attempt to remain as close as possible to the ST, are spontaneous association and reformulation. Among reduction strategies, which are characterized by their inherently remedial nature, are avoidance and unmarked rendering of marked items. Finally, evaluation strategies involve, for instance, reflecting on the adequacy and acceptability of translation equivalents. Though the direction in taxonomizing translation strategies is quite different in this latter categorization, still, a lot of overlap can be found in the given so-called taxonomy of translation strategies regarding literary texts.

Séguinot (1996) proposes four types of translation strategies as being typical of 'professional' translation, namely:

1. Interpersonal strategies (brainstorming, correction, phatic function),

2. Search strategies (dictionaries, world knowledge, words)

3. Inferencing strategies (rereading ST and TT, consult) and

4. Monitoring strategies (reread ST and TT, consult, compare units).

In line with these studies, Lörscher (1996) compares the strategies adopted by professional and non-professional translators (foreign language students). He points out that, although the two groups do not differ qualitatively in their use of translation strategies, they do differ quantitatively, i. e. in the distribution and frequency of the strategies employed. This, also, has been shown in this study, though the dichotomy of professional vs. non-professional translators was not the focus of the study.

Séguinot (1991) suggests that native speakers of English translating into their mother tongue show more efficient monitoring and revising strategies, and work more at the textual level, whereas non-native speakers seem to rely more on learned principles and lexical-level processes something which was not exclusively found in this study.

Drawing upon Lörscher's definition, Jääskeläinen (1993) proposes a classification of translation strategies distinguishing between global and local strategies, the former applying to the whole task (considerations about style, readership etc.), the latter to specific items (i. e. lexical searches). On the basis of this distinction, she is able to claim that global strategies are much more frequently used by professionals and semi-professionals (translator trainees) than by non-professionals in her study. After making a plan, the former appear to follow it systematically through the task, whereas the latter seem to proceed in a more haphazard way.

Overlaps between findings in this study and the previous research on the use of TAPs in Translation Studies

Although Think Aloud Protocols (TAPs) have become a major instrument in process-oriented Translation Studies (TS), serious questions challenge the validity of their results. Putting methodological issues aside, the unsystematicity of the findings on one hand and lack of a unified cognitive mechanism on the other hand demands a more inclusive study. Indeed, despite the genre of this study, i.e. literary texts, the purpose of this study on a broader scope was to see if the translation strategies found in this study could get closer to a more unified pattern of cognitive processes behind the act of translation. Accordingly and avoiding any possible bias, a bottom up approach was adopted in the analysis of the strategies reported by the subjects in the study. As it was elaborated, a closer look at the strategies found demonstrates a lot of overlap even though, we cannot and should not ignore the effect of the genre and the context on the type and frequency of strategies used.

To summarize the strategies found in the corpus, a summary of the main and other compensation strategies are given below followed by some brief explanations:

1. Using Imagery and Look-up

Extract (4) 


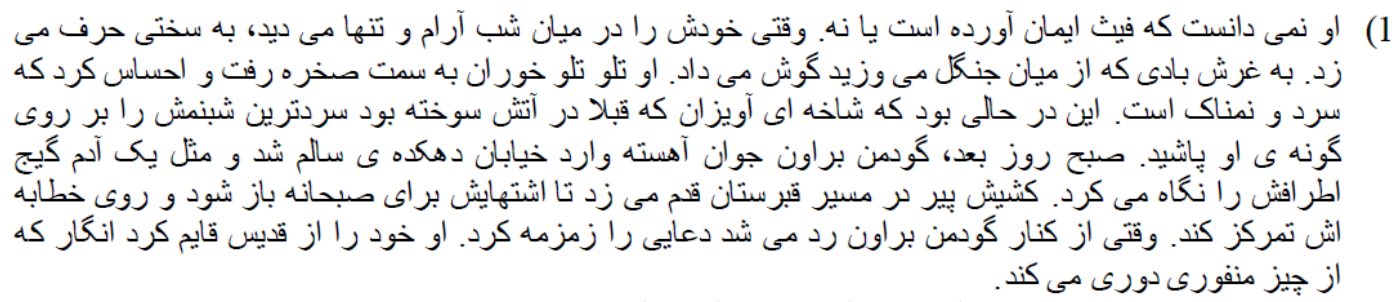

Subject 10): At first, I read the whole text. I imagine the pictures in the story. I want to write whatever I got from the text. Now, I read the source text again. I read it till breakfast. I refer to bilingual dictionary to find good equivalence for the words that I don't know their meaning or I ' $m$ not sure about them. This text is very hard. I try to make short sentences.

2. Assessing comprehension and problem solving

Subject 5): I read the whole text. It is full of words that I don't know their meaning. I look up words in dictionary. I translate some sentences back to front for better understanding of Persian readers. Text is so descriptive and I try to keep this condition in Persian words. I want to transfer these pictures and in fact the atmosphere of the story in the target text as a way that they are in the source text.

I don't know what it means, it's like........ I don't know what it means. But I have to do something, So I start translation anyway

3. Monitoring the task

Subject 5): I read it the text again, and try to see if my translation is good,I monitor my translation all the time to make sure that nothing is nissed.....

As it has been stated ion the literature review, these are some kind of metacognitive trategies. The following are however some examples of cognitive strategies:

4. Hesitation for finding better equivalence or Pausing in silence

Extract (4)

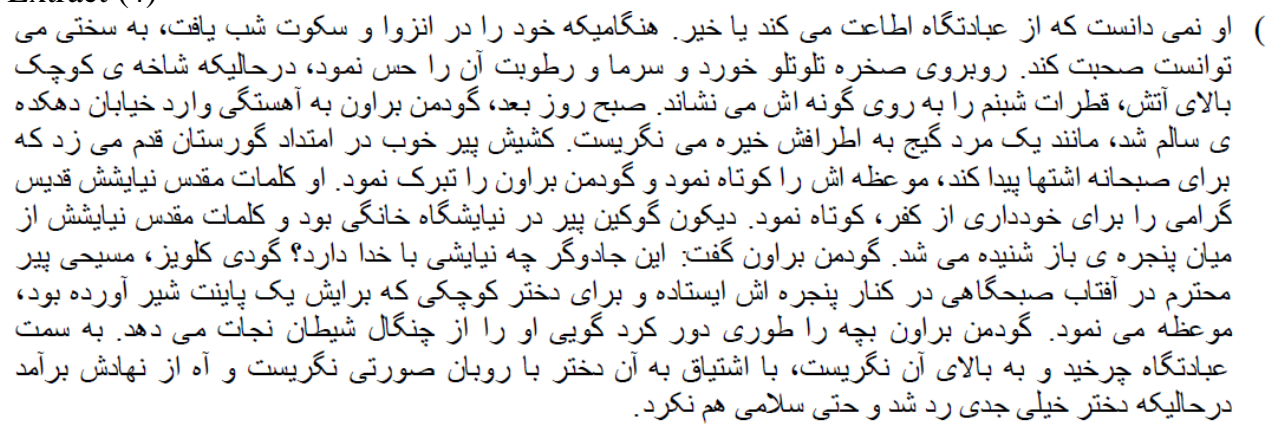

Subject 5): I read the whole text. I hardly can communicate and relate with this text. Sentences are nonsense for me. I have to look up some words in dictionary and read the source text again, then I think, let's see. [pause, rereads silently] Ah, I start to translate the text without looking at the source text, I don't know this way or method is true or not but this is my method for translation. Now, I want to check and compare my translation with the source text. Primitive sentences are so ambiguous for me. I hardly translate them. [pause] But from line 4 to end, translation is easier. I want to find adequate equivalents for descriptive words. Actually, I don't like this text and always my feeling affect on my translation.

5. Rereading portions of text aloud without adding any comments

Subject 6): I read the text aloud . I hardly can understand this text. Sentences eccentric....

6. Co-text Recourse; relating text to previous or subsequent excerpts (going back and forth within the text)

Subject 7): Like previous text, at first, I look at the whole text in order to find words which I don't know the meaning of them. Then, I refer to dictionary to find the meaning of those words. I cannot find the meaning of words "doth" and "catechizing". I try to read the whole text many times to get the concept and main idea. Sometimes I refer to the previous texts and sentences. Now, I want to start translating and writing my sentences into target language with considering to the background conception of the text and meaning of the words. Some words that I cannot find their meaning I replace another word with them with considering the whole text and the preceding sentences. I write my conception of the phrase "with the coldest dew" and the sentence "What God doth the wizard pray to? quoth Goodman Brown" instead of word by word translation. When I read the text for the first time I thought that the meaning of "Faith" is "belief" but when I read it again and refer back I noticed that "Faith" is a proper noun. and now I go back and see if I can understand that sentence that I have not been able to understand in the middle of the text,

7. Using background knowledge, Linguistic Knowledge and self re-course besides other compensation strategies

Subject 11): As the previous, at first I read the whole text. And analyze sentences for the unfamiliar words and grammatical points...some times $\underline{I}$ have to refer to my background language and world knowledge.. $\underline{\text { my }}$ 
experiences help me find out the meaning of some words..As this text is full of happening and works with a subject (he), I decided not write "و "و at the beginning of each sentence because I think the repetition of a word in translation makes the text boring and the reader is not eager to continue it. In the first sentence, I look up "waltz, shuffle and sweep". And since in Persian walts is unknown I give an explanation in parentheses for it. In the second part, I look up the words "retort, dispel and cuffs". I try to translate the concept based on my own knowledge. As I mentioned I don't translate "he" at the beginning of sentences to avoid repetition. And sometimes in translation, I change the sequence of phrases in a sentence to be read more fluently. In the third part, I look up "clacking, air, pantry and utter". I try to have an informal translation because there are some sentences that are his thoughts or he thinks with himself not with an official person. In the last paragraph, I look up the words "flaccid, erect, part, vivacious, puckers, creases and braid". Here, I am in doubt to translate "aunt" as "عمه" or "خاله" important but in Persian culture it makes difference but as I am aunt (as"عمه" "عمه") I translate as ". By finding new words, the meaning became easy. I try to translate concept but I observed the faithful translation like the fourth sentence of this paragraph.

8. Resourcing and using reference books

Subject 10:

Extract (1)

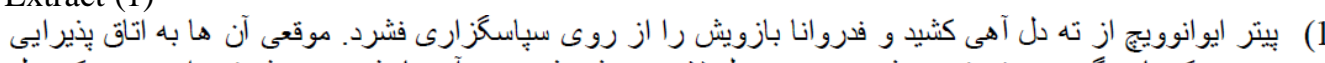

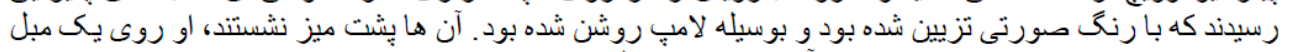

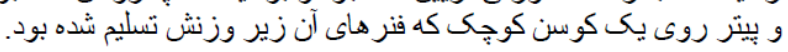

Subject 10): At first, I read the text and mark the words that I do not know the meaning of them by a red pen. Then, I start to find the meaning of words in different dictionaries but I have difficulty in finding a good equivalence for the words, So I refer to literary thesaurus and a handbook. And I think if I translate sentence by sentence it is better because I can find a better equivalence regarding to context.

\section{Looking for similarities with L1 (Switching to L1)}

Subject 6): Understanding the sentences and whole the paragraph is hard for me. I read it more then I try to translate. Before that I try to conceptualize it in my mother tongue to grasp all the story I look up for gloom, dispel, arrange, cuff and bows. I don't understand the meaning of bows so I use a meaning that I think is good for here. I don't know what's the meaning of cuff I look up in other dictionary such as English to Persian one then I map it to My mother tongue equivalents and change the meaning of arrange and then I translate word for word.

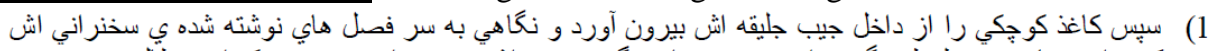

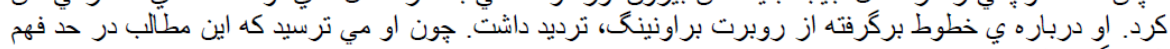

$$
\begin{aligned}
& \text { شنوندكان نباشد. }
\end{aligned}
$$

Subject 6): I don't translate paragraph easily. Translation of last part of this sentence is hard. "he feared they would be above the heads of his hearers" I translate it in Persian .some times I try to paraphrase it in Persian but when I study more I understand that my translation is wrong so I change it. I translate the conception of paragraph. I don't care about exact words so I change them repeatedly.but now I see it is .......

Subject 5): I read the whole text. I hardly can communicate and relate with this text. Sentences are nonsense for me. I have to look up some words in dictionary and read the source text again, Now, I want to check and compare my translation with the source text. Primitive sentences are so ambiguous for me. I hardly translate them. But from line 4 to end, translation is easier. I want to find adequate equivalents for descriptive words. Actually, I don't like this text and always my feeling affect on my translation.

10. Evaluating (Evaluating with reference to academic literary knowledge (i.e. referring to author's style, figurative language, characterization, setting, point of view, irony or author's intention)

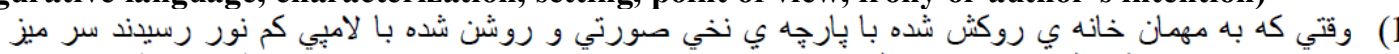

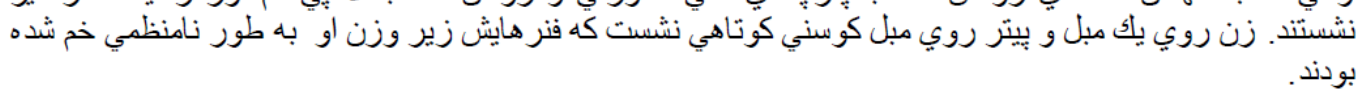

Subject 6): I don't know what the meaning of cretonne is so, I look up in dictionary. I don't understand the meaning. I search for figurative meanings , and other figures of speech........the meaning of spasmodically I check in Babylon dictionary but I cannot find a good meaning so I translate the synonyms of spasmodically; I find convulsively and fitfully instead of it then I find the meaning and translate. I check meaning of pouffe but it is too long so I read its meaning for several times then I translate it. I know the meaning of yield I look up in dictionary again. At the end I translate all sentences. Then I evaluate my translation and in so doing compare it with some original works....

11. Highlighting as another compensation strategy

Subject 6:

1. I study each paragraph completely then I think about the sequence of events and try to imagine places, characters, concept and main idea of whole paragraph. I look up in dictionaries (BATENI, Oxfords, and Babylon (Webster, Word net, Concise Oxford ) and at the end I translate each sentence.

2. My tenses are simple present and simple past and I try to pay attention to the sequence of tenses. $\underline{\mathbf{I} \text { underline some }}$ difficult words and write some notes besides them

12. Analyzing and reasoning 


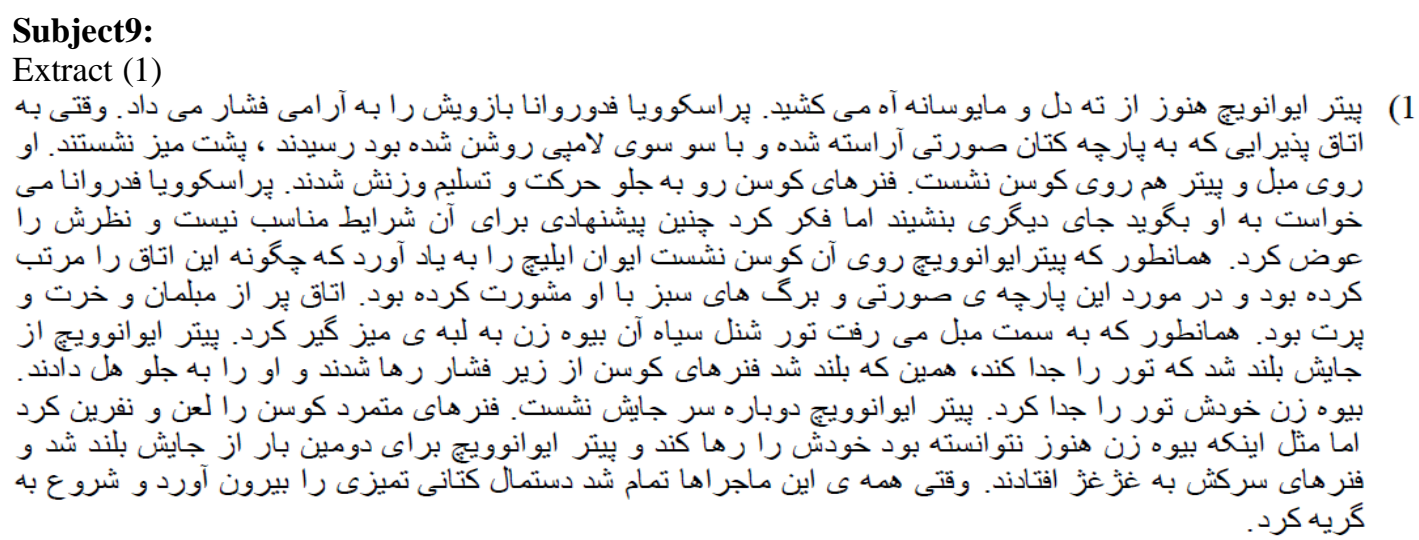

Subject 9): At first, I read the story; I mean the text, to know the type of text. I analyze whole the text and think about the best possible ways to translate the text .I can understand 90 percent of it and the only problem that I have is about new words. I can classify this problem into two parts: I look up for some words in dictionary to find a good definition .I can't find a good definition for .......... I write translation of sentences but it is not as good as English understanding so I add some preposition.

13. Guessing Game

Subject 9): I have some problems with some expressions ...1) The words which I can guess the meaning and the words which I cannot. I guess the meaning of those words due to my imagination and context and write my equivalence down. Then, I look up in a bilingual dictionary for those unknown words. I try to write whatever come to my mind, then rewrite and rewrite and match the original text with target one. I believe these two sentences:1) the springs of the pouffe, relieved of his weight....2)The widow had not quite freed.... Cannot be translated word by word, so I translate them by using Persian expressions.

\section{Deductive reasoning and inductive inferencing}

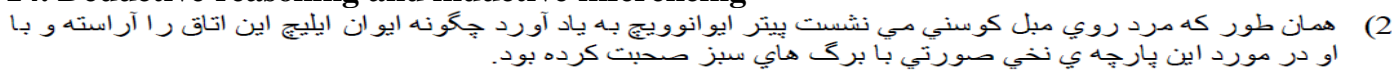

Subject 6): I look up in dictionary and make sure about the meaning of arrange then I translate. But translating the last sentence is hard because I can't find the best meanings. So I try to figure out something in my mind. I look up in other dictionary I change my translation more than 10 times it doesn't good for me .Translating is not easy I read for several times then I look up for arrange, consulted and regarding I know their meanings but they are not suitable for this paragraphs. Finally I get the point from some phrases..and contextual clues....

$$
\text { 3) اتاق بر زر از اسباب و اثاثيه و زلم زيمبو بود در راه رسيدن بيوهزن به سمت مبل، نوار دستمال كرن مشكي اش به لبه }
$$

Subject 6): I love the words knick-knacks and Persian meaning. I know the meaning of knick-knack I don't check it again. I imagine the room as the biggest room which is full of rubbish materials. I look up in dictionaries for: lace, shawl, caught on. I write the meanings in Persian then $I$ analyze everything in mind and come up with some idea..I translate the text.

\section{Contextual recourse and paraphrasing}

$$
\begin{aligned}
& \text { 4) بيوه زن شروع به جدا كردن دستمال كردنش كرد و بيتر ايوانوويج بار ديكر نشست و آشفتخكي فنرهاي مبل كوسني }
\end{aligned}
$$

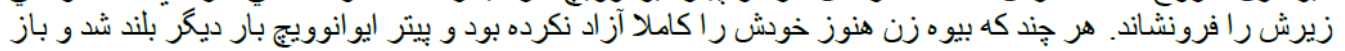

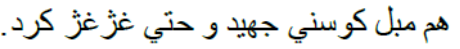

Subject 6): I don't understand what are the roles of the shawl and the springs here? Why they were mentioned more than Ivan's name? There is no conversation between characters. The scene is going to be finished by the sound of pouffe and its rebel. I understand the meaning of paragraph but $\mathbf{I}$ don't know what the meaning of suppressing, rebellious is and creak. So I check the context to get the meaning. Before that however, I reword the whole passage and simplify the text......

\section{Other Compensation Strategies}

There are some other strategies found in the corpus which are worth mentioning in this part, however, we just suffice to mentioning them. These are making analogies with other L2 words, using knowledge about word formation .Using knowledge about typographical conventions. Looking for similarities with L1. Using knowledge about punctuation, and analyzing textual organization and text type

All in all, the strategies found in this study can be classified as the following:

1. Using Imagery, 2.Look-up, 3.Contextual recourse, 4.Analyzing and reasoning, 5.Resourcing, 6.Self-Recourse 7 Contextual recourse 8.Deductive reasoning, 9.Inductibve inferencing, 10.Co-text recourse, 11.Switching to L1, 12.Paraphrasing, 13.Problem-solving and 14.Other Compensation strategies 


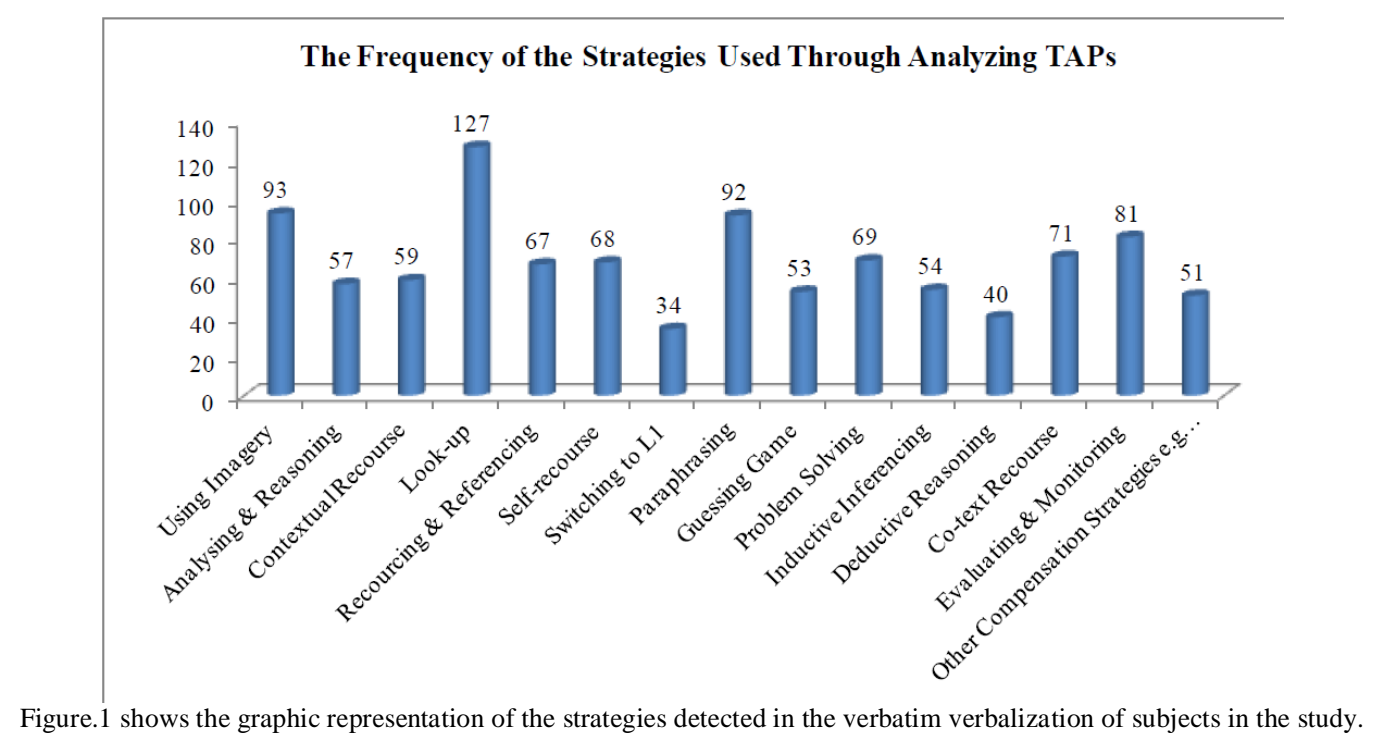

As the graph.1 shows, Look-up was the most frequent strategy used by the subjects in the study while translating the literary excerpts. Using imagery and Paraphrasing are the second and third most frequent strategies used by the subjects respectively. As it can be seen, switching to L1 while translation is the lowest strategy has been reported in TAPs by the subjects. Deductive reasoning strategies are the second lowest strategy reported. Such strategies as Resourcing and referencing, evaluating and monitoring, problem solving and co-text recourse stand in between. Avoiding terminology confusion, one can refer to other compensation strategies used by the subjects that either overlaps the current classification of strategies as adopted in this study or in some way approach in many cases to the classification reported above. Furthermore, there were other less important strategies which could be added to table.1.However, either for semantic overlap or low frequency rate, they are just referred to here briefly below .These are Concentration on grammatical features of the text or word order, focusing on the theme and content of the texts under translation, Rereading the texts under translation, searching for the clues, hesitation to find better equivalents, writing the meaning of new words in Persian, and final edition and revision.

\section{IMPLICATIONS OF THE STUDY}

The significance of this study is threefold: Theoretically, the findings of this study will contribute to the mainstream TAP research in general and TAP in translation studies in particular. Though much has been written on TAP studies in different genres and different groups of students, we are still far from a unified body of literature in the field. This and other similar studies can help the development of a more unified theory of the application of TAP in translation studies in general and literary translation in particular with a much more cognitive orientation.

Practically, one of the most significant purposes of TAP studies in general and translation in particular is to extract and delve into the processes through which the act of translation and interpretation can be much more convenient. This study in line with other studies in the field, will pave the way for those researchers who are interested in the cognitive and practical constraints with which translators are entangled with especially in the translation of literary texts.

Also, this study has some pedagogical implications for translation students in general and EFL learners in particular on one hand and translation teachers and trainers on the other hand. The findings of this study and similar studies can give a good image to learners and teachers to have a more vivid picture of the translation process and will show them how to avoid the use and application of incorrect and demanding strategies in their translation process.

\section{REFERENCES}

[1] Bassnett, Susan and André Lefevere (eds). (1990). Translation, History and Culture. London and New York: Pinter.

[2] Carl, M., Jensen, K.T.H., \& Jakobsen, A.L. (2008). Studying human translator behavior with user-activity data. Natural Language Processing and Cognitive Science (NLPCS 2008) conference - part of the 10th International Conference Enterprise Information Systems 12-16 June, 2008, Barcelona, Spain.

[3] Gerloff, P. (1986). 'Second language learners' reports on the interpretive process: Talk-aloud protocols of translation'. In J. House \& S. Blum-Kulka (eds.), Interlingual and Intercultural Communication. Tübingen: Gunter Narr. 243-62.

[4] Hansen, G. (2003). Controlling the process: theoretical and methodological reflections on research into translation processes. In F. Alves (ed.), Triangulating translation. Perspectives in Process Oriented Research (pp. 25-42). Amsterdam and Philadelphia: John Benjamins.

[5] Hatim, B. \& Mason, I. (1990). Discourse and the Translator. London: Longman Inc.

[6] Herzfeld, M. (2003). The unspeakable in pursuit of the ineffable: representations of untranslatability in ethnographic discourse. In P. G. Rubel \& A. Rosman (Eds), Translating culture: perspectives on translation and anthropology. Oxford: Oxford University Press. 
[7] Jääskeläinen, R. (1993). Investigating translation strategies. In Tirkkonen-Condit, S. (ed) Recent trends in empirical translation research. Joensuu: University of Joensuu Faculty of Arts. 99-120.

[8] Jääskeläinen, R. (1993). Investigating translation strategies. In Y. Gambier \& J. Tommola (eds.), SSOTT IV. Translation and Knowledge (pp. 99-120). Turku: University of Turku.

[9] Jääskeläinen, R. (1999). Tapping the process: an explorative study of the cognitive and affective factors involved in translating. Joensuu: University of Joensuu.

[10] Jackobson, R (1959). On Linguistics Approach of Translation. Cambridge: Harvard University Press.

[11] Jensen, A. (1999). Time pressure in translation. In G. Hansen (ed.), Probing the Process in Translation: Methods and Results (pp. 103-120). [Copenhagen Studies in Language 24], Copenhagen: Samfundslitteratur.

[12] Krings, H. P. (1986). Translation problems and translation strategies of advanced German learners of French (L2).In J. House \& S. Blum-Kulka (eds.), Interlingual and Intercultural Communication. Tübingen: Gunter Narr. 263-75.

[13] Künzli, A. (2007). The ethical dimension of translation revision. An empirical study. The Journal of Specialised Translation, 8 , 42-56 [special issue on translation revision].

[14] Kussmaul, P. \& Tirkkonen-Condit, S. (1995). Think-Aloud Protocol Analysis in Translation Studies. TTR, 8 (1), $177-199$.

[15] Lörscher, W. (1996). 'A psycholinguistic analysis of translation processes'. Meta 41, 1: 26-32.

[16] Mondahl, M. and K.A. Jensen (1996). 'Lexical search strategies in translation'. Meta 41, 1: 97- 112.

[17] Miremadi, S. A. (2001). Theories of Translation and Interpretation. Tehran: SAMT.

[18] Mondahl, M., \& Jensen, A. J. (1996). Lexical search strategies in translation. Meta 41(1), 97- 112.

[19] Oxford, R. (1990). Language Learning Strategies. What every teacher should know. Massachusetts: Heinle \& Heinle Publishers.

[20] Pontinen, T., \& Romanov, T. (1989). Professional vs. non-professional translator: a think- aloud protocol study. Joensuu, University of Joensuu, Savonlinna School of Translation Studies.

[21] Séguinot, C. (1991). 'A study of student translation strategies'. In Tirkkonen-Condit, S. (ed) Empirical research in translation and intercultural studies. Tübingen: Gunter Narr. 79-88.

[22] Séguinot, C. (1996). 'Some thoughts about think-aloud protocols'. Target 8, 1: 75-95.

[23] Tirkkonen-Condit, S. (1997). 'Who verbalises what: A linguistic analysis of TAP texts'. Target 9, 1: 69-84.

Ali Asghar Eftekhary is an Assistant Professor in English Department, Faculty of Foreign Languages, Islamic Azad University, Bandar Abbas Branch.

Shayesteh Aminizadeh is an MA student in Islamic Azad University, Bandar Abbas Branch. 